Brit. J. industr. Med., 1958, 15, 276

\title{
AN INVESTIGATION OF SOME HEALTH HAZARDS IN AN INERT-GAS TUNGSTEN-ARC WELDING SHOP
}

BY

\author{
P. J. R. CHALLEN, D. E. HICKISH, and JOAN BEDFORD \\ From the Slough Industrial Health Service
}

(RECEIVED FOR PUBLICATION DECEMBER 7, 1957)

Inert-gas Arc Welding of Aluminium

Aluminium is used widely in metal fabrication processes, chiefly on account of its lightness, the ease with which it may be cast, and its extreme ductility. It is also highly resistant to corrosion, owing to the formation of a protective film of oxide on the surface of the metal. This latter property, however, becomes a disadvantage when it is desired to weld the metal, as the oxide film hinders consolidation of the metal on fusion, and even when broken down it re-forms almost instantaneously in air. Aluminium may be welded by either gas or arc processes, but arc welding is more satisfactory as the area over which the heat is generated is smaller and the speed of welding can thus be increased. The thermal conductivity of aluminium is high, being five times greater than that of steel, and hence with arc welding distortion and any tendency to crack are reduced.

With both gas and arc welding the oxide may be dispersed by means of fluxes, but the disadvantage of this procedure is that the flux residues are corrosive, and after completion of the weld thorough cleaning of the metal is essential. Joints have thus to be so designed as to avoid trapping flux.

These problems have led to the development of forms of arc welding which utilize an inert-gas arc

\footnotetext{
Fig. 1.-Diagram of inert-gas arcwelding apparatus.

(a) Inert-gas tungsten-arc welding. (b) Inert-gas metal-arc process.
}

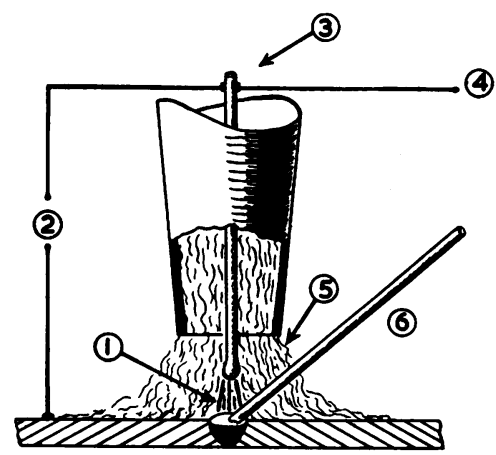

(a)

1-Welding arc

2-Surge injection (if used)

3-Tungsten electrode

4 -A.C. or D.C. supply, H.F. impulses superimposed

5-Shielding gas, usually argon, but mixtures with small quantities of other gases 6-Filler wire shield, usually of argon or helium. This gas shield allows the arc to disperse the oxide film, and by the exclusion of oxygen prevents it from being reformed. The use of these welding methods gives greater freedom in design, and the welding torch may even be used to form a weld inside a partly sealed container. As these welding methods are capable of automatic operation higher welding speeds may be achieved, and this feature, together with the use of higher welding currents than are employed in manual welding, enables welding to be carried out on thicker metal than would otherwise be the case.

Two main types of inert-gas shielded welding are used, and are shown diagrammatically in Figs. $1 a$ and $1 b$. The inert-gas tungsten-arc method (Fig. 1a) uses a non-consumable tungsten electrode for producing the arc, and the welding is normally carried out by the use of a filler rod of aluminium.

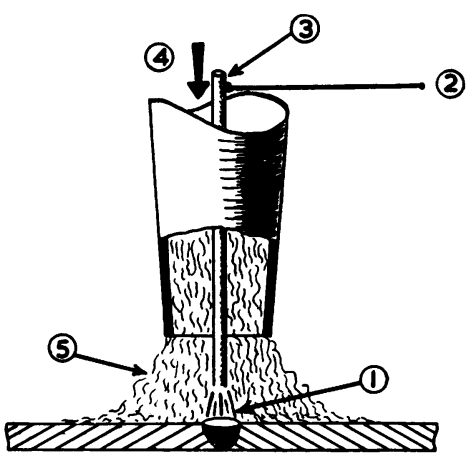

(b)

1-Welding arc 2-D.C. supply 3-Consumable electrode wire 4-Wire feed 5-Argon or $\mathrm{CO}_{2}$ shielding gas 


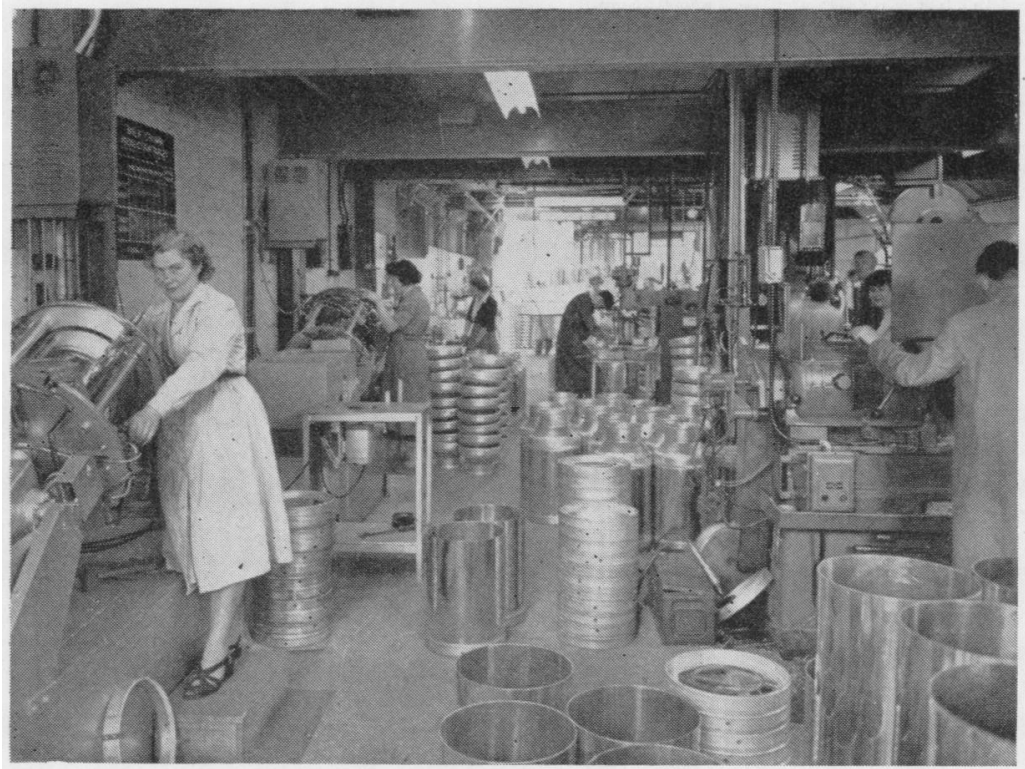

Fig. 2.-General view of the welding shop.
Ginther, 1952). The absence of rod coatings, which are commonly employed in ordinary arc welding, means that very much less fume is produced, and there is therefore less absorption of ultraviolet radiation by the fume. By the use of an electrode in the form of a continuous coil of wire, the process may be used for longer periods than would be possible in ordinary arc welding. The welding of non-ferrous metals requires that the metal surfaces shall be free from grease, and it is common for trichloro-ethylene degreasing of the component parts to precede the welding operation.

\section{Environmental Survey}

Procedure.-The investiga-

A proportion of the parent metal may be melted into the weldbead, and this may affect the weld properties. The arc temperature is normally about $5,000^{\circ} \mathrm{C}$.

A development of this method utilizes a consumable electrode in place of the tungsten electrode, and is known as the inert-gas metal-arc welding process (Fig. 1b). The electrode is in the form of a wire which is coiled on a reel and passes through the conduit which conducts argon gas to a welding gun. The trigger of the gun operates both gas and electrical controls. Very high current densities, of the order of $100,000 \mathrm{amps} . /$ in. $^{2}$ are used, and hence a smooth steady arc is produced and welding in the vertical or overhead positions is possible.

The current densities used in this type of welding are greater than normally encountered with ordinary stick electrodes, and a more confined source of spectral energy in both ultra-violet and infra-red ranges is produced. Whereas the spectral emission from the iron arc is principally in the blue and near visible range, that from aluminium is principally below 3,900 $\AA$, and the bulk of the radiation is concentrated in a few lines. This factor is of considerable importance from the point of view of industrial hygiene, as it is the radiations having wavelengths between 1,750 and $2,500 \AA$ which act upon air to produce ozone. Argon also has strong emission spectral lines at $1,850 \AA$. Helium is sometimes used for the gas shield, and with this gas less ozone is produced than with argon (Ferry.: and tion to be described was the outcome of an enquiry sent to our laboratories by the management of a firm manufacturing aluminium milk churns. The sister in charge of the Works Medical Department had noticed that workers in the welding shop were frequently complaining of upper respiratory symptoms, and she suspected that these complaints might be the result of exposure to phosgene. On inspecting the process, however, we considered that the main atmospheric contaminant was probably ozone, the odour of which was readily discernible in the welding shop. The welding shop concerned had a low ceiling, was crowded with machinery, and the adequacy of the general ventilation was doubtful.

The firm has designed a series of automatic welding machines embodying a modification of the inertgas tungsten-arc process. The aluminium components are placed in a jig, and an arc is struck between the tungsten electrode and the edges to be joined. With this type of machine no filler rod is required, and the metal for the weld is obtained by fusion of the edges of the components themselves. A general view of the welding shop is shown in Fig. 2, and a close-up view of one of the automatic welding machines in Fig. 3. Before welding, all the parts are degreased in a trichloro-ethylene tank in an adjacent bay, which communicates with the welding shop through an open doorway. A preliminary investigation, in collaboration with Mr. R. J. Sherwood, revealed concentrations in the welding shop of up to 1.07 p.p.m. of ozone and up to 69 p.p.m. of 
trichloro-ethylene. This finding led us to consider further the possibility of phosgene formation, and in the present investigation air samples were analysed for ozone, trichloro-ethylene, and phosgene.

Trichloro-ethylene was collected on silica gel (Hickish, Smith, and Bedford, 1956) and analysed by the Volhard method (Elkins, 1950). Ozone was collected in fritted glass bubblers containing potassium iodide solution and analysed by an iodometric method. It was appreciated that this method was not specific for ozone, and that nitrogenoxides would interfere, but we were aware of the work of Kleinfeld, Giel, and Tabershaw (1957) which indicated that significant concentrations of oxides of nitrogen were absent during inert-gas

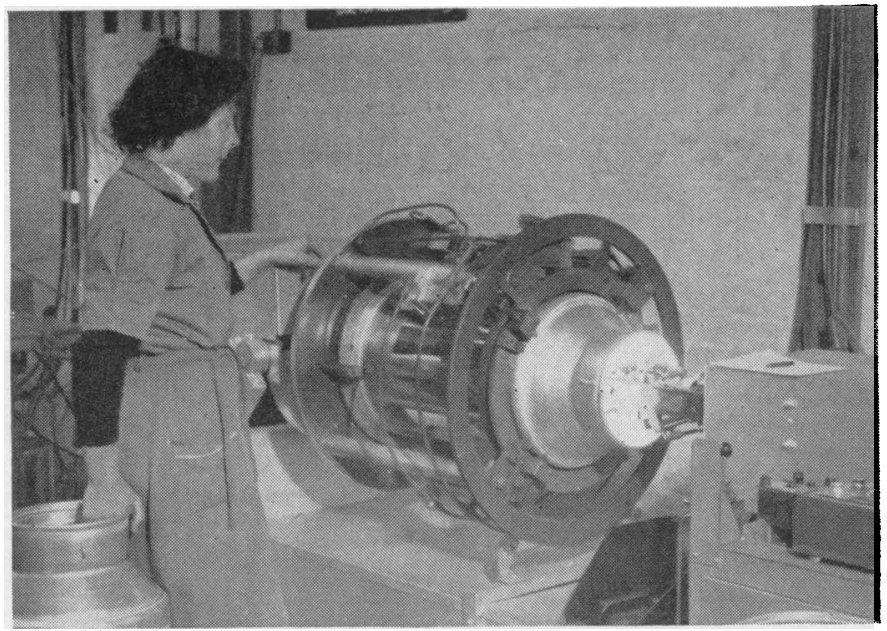

FIG. 3.-Close-up view of a typical automatic welding machine.

shielded metal arc welding and that ozone was the determined by a modification of the D.S.I.R. method principal hazard. The presence of phosgene was (Department of Scientific and Industrial Research,

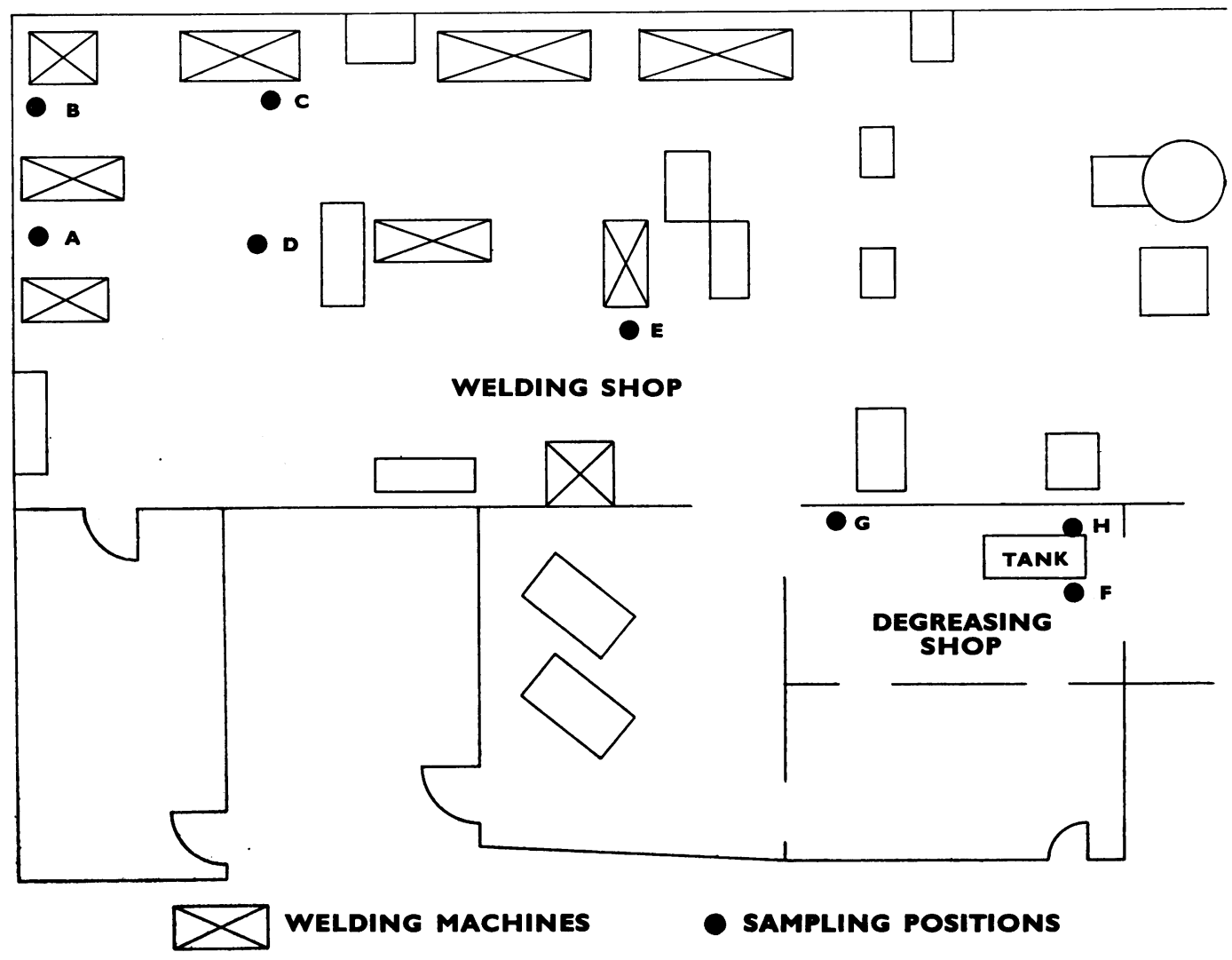

Fig. 4.-Plan showing sampling positions in the welding and degreasing shops. 
1939), an electric pump sampling at the rate of $1 \mathrm{litre} / \mathrm{min}$. being used in place of a hand-pump. The determination of small quantities of phosgene in the presence of larger quantities of trichloroethylene was achieved by a method which was suggested to us by the Chemical Defence Experimental Establishment at Porton. Samples were collected in Neale bubblers containing $5 \mathrm{ml}$. of an aqueous solution of caustic soda and hexamine, and were subsequently titrated electrometrically with silver nitrate solution. The method had previously been calibrated in our laboratories against standard concentrations of phosgene set up in a 45-cu. $\mathrm{ft}$. calibration chamber. We confirmed that the addition of 200 p.p.m. of trichloro-ethylene to the phosgene concentration did not affect the analysis.

All the air samples were collected in the breathing zone of the workers over periods of approximately 30 minutes at five operating positions in the welding shop and at one position (F marked on Fig. 4) in the degreasing shop. It was arranged that freshly degreased components would be used during the collection of samples 5 and 6 in order to assess the resulting air contamination from this method of working-probably the severest conditions likely to be encountered. The location of the sampling positions, and those described below, is shown in Fig. 4.

On a subsequent occasion further air sampling for trichloro-ethylene was carried out in the degreasing shop, which was situated adjacent to the welding shop. The degreasing tank was of the vapour phase type, and was provided with covers. Three sampling positions were selected as follows: Position F, breathing zone of the operator; Position $\mathrm{G}$, adjacent to the doorway between the degreasing and welding shops, thus giving an indication of the concentrations of vapour which could be conveyed to the welding shop under certain conditions of ventilation; Position $\mathrm{H}$ was 12 in. above the tank edge level at the rear of the tank, and was selected to enable a study to be made of the usefulness of the tank covers.
Sampling was repeated under three different operating conditions, as follows:

Run 1.-The tank was operated with the covers open. The doors and windows of the degreasing shop were closed, but normal natural ventilation was provided in the welding shop.

Run 2.-The tank was operated with the covers open, and maximum natural ventilation was provided in both degreasing and welding shops.

Run 3.-The tank was operated with the covers closed during degreasing, ventilation conditions being as for the first run.

Results.-The results of the air sampling in the welding shop, and of the single sample taken in the degreasing shop are shown in Table 1 , which also includes the maximum allowable concentrations for trichloro-ethylene, ozone, and phosgene recommended by the American Conference of Governmental Industrial Hygienists (1956). The figure for ozone is further discussed below.

The filter paper test for phosgene (Department of Scientific and Industrial Research, 1939) gave only a pale cream discoloration with samples of several litres of air, thus indicating the presence of only a trace of phosgene. The colour produced was slightly deeper near the machines where freshly degreased parts were used.

Trichloro-ethylene concentrations found in the degreasing shop are shown in Table 2.

TABLE 2

TRICHLORO-ETHYLENE CONCENTRATIONS IN DEGREASING SHOP

\begin{tabular}{c|c|c}
\hline Run & Position & $\begin{array}{c}\text { Trichloro-ethylene* } \\
\text { Concentration } \\
\text { (p.p.m.) }\end{array}$ \\
\hline \multirow{2}{*}{1} & F & 266 \\
& G & 230 \\
\hline 2 & F & 412 \\
\hline 3 & G & 247 \\
& H & 466 \\
\hline & G & 184 \\
& H & 101 \\
\hline
\end{tabular}

TABLE 1

RESULTS OF AIR ANALYSIS IN WELDING SHOP

\begin{tabular}{|c|c|c|c|c|c|}
\hline Sample & Position & $\begin{array}{c}\text { Trichloro-ethylene } \\
\text { (p.p.m.) }\end{array}$ & $\begin{array}{l}\text { Ozone } \\
\text { (p.p.m.) }\end{array}$ & $\begin{array}{l}\text { Phosgene } \\
\text { (p.p.m.) }\end{array}$ & Remarks \\
\hline $\begin{array}{l}1 \\
2 \\
3 \\
4 \\
5\end{array}$ & $\begin{array}{l}\mathbf{A} \\
\mathbf{B} \\
\mathbf{C} \\
\mathbf{D} \\
\mathbf{A}\end{array}$ & $\begin{array}{r}0 \\
8 \\
1 \\
3 \\
97\end{array}$ & $\begin{array}{l}1.4 \\
0.8 \\
0.9 \\
1.7 \\
1.2\end{array}$ & \multirow{4}{*}{\multicolumn{2}{|c|}{ 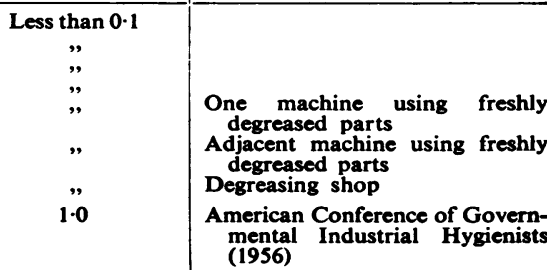 }} \\
\hline 6 & $\mathbf{E}$ & 13 & 0.9 & & \\
\hline 7 & $\mathbf{F}$ & 238 & - & & \\
\hline $\begin{array}{l}\text { Maximum } \\
\text { allowable } \\
\text { concentration }\end{array}$ & & 200 & 0.1 & & \\
\hline
\end{tabular}




\section{Clinical Survey}

When the clinical survey began, automatic welding machines had been in use for three and a half years but had only been installed in the workshop under investigation for two and a half years. The firm employed some 190 workers and 50 staff and had increased its output by the introduction of automatic production methods to 2,000 churns per week, yet it was still unable to supply the demand.

So as to disrupt workshop organization as little as possible it was decided that employees would be interviewed but not examined or subjected to laboratory tests unless there was a clear indication in any case for these procedures. It was also decided to restrict the interviews to those employees who operated the welding machines, as the firm's nursing sister informed us that the other employees in the workshop had not complained to her of any symptoms.

Fourteen employees (11 female and three male) were therefore interviewed out of a labour force of 36 (17 female and 19 male) in the workshop. The ages of the 11 female employees ranged from 21 to 50 and the length of time they had been welding from one to 30 months; the three male employees were aged 41,37 , and 34 years, and two had been welding for 24 months, the other for a period of 42 months. Only three out of the 14 employees had been free from symptoms during their period of exposure. The others were troubled periodically and complained of a dry mouth and throat, irritation of the nose and eyes, and lacrimation. Eight objected to a "disagreeable" smell which they could not describe more accurately, and which they stated was often present in the early morning on starting work. It disappeared after one or two hours and it was more noticeable in the winter months when the windows were kept closed. We thought that this smell might have been due to the presence of phosgene but we were unable to detect any measurable concentrations of this substance. Five persons were subject to attacks of diurnal lassitude and two to feelings of substernal oppression.

Two case histories are recorded here in more detail because they are thought to be of interest, although their significance is doubtful.

Case 1.-A woman, aged 32, had been employed for 15 months and had been welding for 10 months. She stated that one day she suddenly developed difficulty in breathing, and wheezing. She was away from work for two weeks and was treated by her family doctor for bronchitis. She returned to welding but two days later she again began wheezing and continued to do so for four days, when she was transferred to other work and the symptoms subsided almost immediately. She had no further trouble but she has now left the firm. She had never suffered from a similar illness or any allergic disorder and the family history was not relevant.

Case 2.-A woman, aged 50, had been employed for 14 years and had operated a welding machine for eight months. Five months after she started welding she developed "a tightness of the chest" and wheezing. She remained at work with these symptoms for two weeks and then went off work for a fortnight and received treatment for bronchitis from her family doctor. This was her first attack of bronchitis. When she returned to work she continued welding but soon afterwards her symptoms recurred. She carried on for some weeks and the symptoms occurred spasmodically until eventually she remained at home for three days under the care of her family doctor. By this time the family doctor had decided that there was some relationship between her ill-health and her work and he advised alternative employment. Her work was changed and since then she has had only one week away from work, on account of laryngitis.

She stated that she had been subject to upper respiratory catarrh and to attacks of frontal sinusitis for many years and on one occasion she was operated on for nasal polypi. There was no family history of allergy.

During the investigation one male employee, aged 36 , who was employed on an automatic welding machine in another workshop was interviewed. Because of the nature of his work he had to operate the machine with his face at about 8 to $10 \mathrm{in}$. from the arc. However, he was well screened from ultraviolet radiation. He complained of periodic attacks of nose and eye irritation, lacrimation, and " tightness of the chest". He stated that these symptoms were more pronounced in the winter when the windows and doors were kept closed. No atmospheric sampling was carried out in the vicinity of this machine.

Two male employees from the degreasing shop were also interviewed; one, aged 48, had been engaged full-time on degreasing for seven years, but three months before the interview he was transferred to alternative employment because of his symptoms. He was complaining of lassitude at work, sleepiness in the evening, irritability, lack of concentration, and that his memory was defective. His wife came to see the nursing sister at the firm because she was worried that her husband had become badtempered and sleepy in the evening. The other, aged 44, replaced the above employee. He complained of lassitude during the day and of feeling sleepy in the evening and stated that he felt much more alert at the week-end. On one occasion when he was working overtime he became dazed and confused and had to be taken home for medical attention.

The symptoms described by these two employees were not unexpected in view of the concentrations 
of trichloro-ethylene found in the atmospheric samples. Similar clinical effects from chronic exposure to this substance have often been reported in the past.

\section{Discussion}

Ozone.-The occurrence of ozone in nature, its properties and commercial preparation and its toxic properties are thoroughly reviewed by Stokinger (1954). The early symptoms in man are burning and smarting of the eyes and nose, headache, and lethargy; low concentrations may even put some people to sleep. Hill and Flack (1912) performed experiments on themselves and they reported that 2 to 3 p.p.m. of ozone quickly caused irritation of the upper respiratory passages; headache and a sense of oppression developed later.

Exposure to ozone is a hazard to those engaged in its preparation and use and to those working near high-voltage electrical equipment and ultraviolet lamps. It is a possible danger to high-altitude flyers. Wilska (1951) has described symptoms in technicians who used a spectrograph with an electric-spark source. The concentration of ozone was found to be 1 p.p.m. after the spectrograph had been in use for an hour. The technicians had irritation of the upper respiratory tract within 15 minutes, and after working under these conditions for a fortnight they were short of breath and had continuous headache.

Ozone is formed in small amounts in arc welding and in greater quantities in inert-gas shielded arc welding. Kleinfeld et al. (1957) described three cases of ozone intoxication in men using the latter process with consumable electrodes. They excluded poisoning by " nitrous fumes" and phosgene by air analysis at the breathing zone of the workmen, but the concentration of ozone was found to be as high as $\mathbf{9 \cdot 2}$ p.p.m.

The present investigation shows that during inert-gas shielded arc welding of aluminium with non-consumable tungsten electrodes the important air contaminant is ozone (Table 1).

During the course of our investigation the maximum allowable concentration (M.A.C.) for ozone was reduced by the American Conference of Governmental Industrial Hygienists (1956) from 1 p.p.m. to $0 \cdot 1$ p.p.m. We were informed (Stokinger, 1956) that this reduction was recommended in view of reports of " nuisance symptoms" occurring at concentrations in the region of 1 p.p.m. Although the operators in our study did not complain of symptoms at exposures between $0 \cdot 19$ and 0.25 p.p.m. we are of the opinion that the decision to reduce the M.A.C. to its present value was a wise one.

Trichloro-ethylene.-Consideration of the con- centrations of trichloro-ethylene in the atmosphere of the degreasing shop shows that at the operating position the concentration was near or above the M.A.C. under most of the conditions studied (Table 2). Above the tank, the concentrations were of the same order whether or not the tank covers were used. This suggests that the main source of air contamination arose from the degreasing vapour and liquid withdrawn from the tank when the work baskets were removed, rather than from the escape of vapour during the degreasing operation. The need for slow removal of the baskets from degreasing tanks is thus again emphasized. In addition, control of the direction of ventilation between welding and degreasing shops was considered necessary in view of the concentrations of vapour shown to exist at the doorway between the two shops.

\section{Environmental Control}

Ferry and Ginther (1952) considered that decomposition of trichloro-ethylene to phosgene, when it occurs, is probably due to radiation from the welding arc rather than to contact with the arc itself, and therefore, when welding is carried out in an open shop, radiation shielding is required in addition to local exhaust ventilation. The application of exhaust ventilation to inert-gas shielded welding must be carried out with caution, lest the gas shield itself be removed from the arc. In collaboration with the engineers at the factory, we carried out further experiments in order to determine an adequate rate of exhaust ventilation which would not affect the quality of the weld.

A test hood 7 in. by 12 in. was placed in position on the machine shown in Fig. 3, $2 \frac{1}{2}$ in. above the lip of the churn, and air was exhausted at the rate of 202 c.f.m., corresponding to a face velocity at the hood of $324 \mathrm{ft} . / \mathrm{min}$. This arrangement had previously been tested by the works engineers and shown not to affect the weld. Smoke tests, using titanium tetrachloride, and air sampling for ozone, with and without the exhaust hood in operation, suggested that complete control of gases and vapours was being attained.

A system of exhaust ventilation was subsequently installed on all the welding machines, and air sampling was again carried out at the positions shown in Fig. 4. The results of the analyses of these samples are shown in Table 3.

Smoke tests were also carried out at the same time on each machine to ascertain the effectiveness of control of the individual exhaust hoods (all of which were of necessity of different shape); in several instances modifications were found to be desirable and this work is now being undertaken. These improvements should result in further reductions 
TABLE 3

OZONE CONCENTRATIONS IN WELDING SHOP AFTER INSTALLATION OF EXHAUST VENTILATION

\begin{tabular}{c|c|c|c}
\hline Sample & Position & $\begin{array}{c}\text { Ozone } \\
\text { (p.p.m.) }\end{array}$ & Remarks \\
\hline 1 & A & 0.21 & \\
2 & B & 0.23 & Ventilation required \\
3 & D & 0.30 & adjustment \\
4 & 0.19 & General atmosphere \\
5 & Outside factory & 0 & \\
6 & A & 0.25 & \\
7 & B & 0.25 & \\
8 & Outside factory & 0 & \\
\hline
\end{tabular}

of the ozone concentrations. Since installation of the exhaust ventilation the only complaint has been from the operator of the machine at position $\mathrm{C}$ where the exhaust was subsequently found to be the least effective.

Adequate control of degreasing operations to prevent undue "drag-out" of vapour has been discussed in a previous paper (Hickish et al., 1956). Since our investigation, exhaust ventilation has been installed in the degreasing shop with the dual purpose of reducing the exposure of the operator, and to ensure that the direction of air-flow is from the welding shop to the degreasing shop and not vice versa. Mechanical operation of the insertion and removal of parts from the tank has been installed, and the speed of removal controlled to $10 \mathrm{ft} . / \mathrm{min}$., thus minimizing "drag-out" of trichloro-ethylene vapour. The working conditions have therefore been greatly improved.

\section{Summary}

A description is given of the inert-gas arc welding process for aluminium, and of the formation of ozone during its use.

An environmental and clinical survey has been carried out in a workshop equipped with automatic inert-gas tungsten-arc welding machines. Ozone was found in the air in concentrations ranging from 0.8 to 1.7 p.p.m. Eleven out of 14 employees complained of upper respiratory symptoms.

No further symptoms were reported after ozone concentrations were reduced to the region of 0.2 p.p.m., and our findings thus support the decision of the American Conference of Governmental Industrial Hygienists (1956) to lower the M.A.C. for ozone from 1.0 to 0.1 p.p.m.

A system of local exhaust ventilation which did not remove the inert-gas shield and thus affect the quality of the weld is described, and the effectiveness of the system is demonstrated by substantial reductions in the concentrations of ozone in the workshop.

An account is included of an environmental and clinical investigation in a degreasing bay adjacent to the welding shop, and of the action taken to improve environmental conditions.

We are indebted to the management, employees, and nursing sister of the firm concerned for their willing and enthusiastic cooperation in this investigation, and to Professor G. P. Crowden for encouragement and advice.

Fig. 1 is published by permission of the Institute of Welding.

\section{REFERENCES}

Department of Scientific and Industrial Research (1939). Methods for the Detection of Toxic Gases in Industry, Leaflet No. 8 Phosgene. H.M.S.O. London.

Elkins, H. B. (1950). The Chemistry of Industrial Toxicology. Wiley, New York.

Ferry, J. J., and Ginther, G. B. (1952). Amer. industr. Hyg. Ass. Quart., 13, 196.

Hickish, D. E., Smith, J. H., and Bedford, Joan (1956). Brit. J. industr. Med., 13, 290.

Hill, L., and Flack, M. (1912). Proc. roy. Soc. 84, Ser. B, 404.

Kleinfield, M., Giel, C., and Tabershaw, I. R. (1957). A.M.A. Arch. industr. Hlth, 15, 27.

Stokinger, H. E. (1954). A.M.A. Arch. industr. Hyg., 9, 366.

Wil1956). Personal communication.

Wilska, S. (1951). Acta chem. scand., 5, 1359. 